\title{
Multiple Genetic Changes Can Occur in the Oral Poliovaccines upon Replication in Humans
}

\author{
By OLEN M. KEW, BALDEV K. NOTTAY, MILFORD H. HATCH, \\ JAMES H. NAKANO AND JOHN F. OBIJESKI \\ Virology Division, Center for Infectious Diseases, Centers for Disease Control, Public Health \\ Service, U.S. Department of Health and Human Services, Atlanta, Georgia 30333, U.S.A.
}

(Accepted 10 June 1981)

SUMMAR Y

Poliovirus isolates of serotypes 2 and 3 from patients whose paralytic poliomyelitis cases were classified as oral vaccine-associated were analysed by oligonucleotide mapping of the virus genomes and by polyacrylamide gel electrophoresis of the virus proteins. Oligonucleotide maps of all isolates were similar to the maps of the corresponding oral vaccine strain. No two isolates gave identical maps. Most maps differed from that of the vaccine strain by at least one oligonucleotide spot. Maps of some isolates revealed numerous differences, indicating that multiple $(>100)$ genetic changes had occurred in the vaccine virus genomes during replication in one or two individuals. In contrast, maps of some neural tissue isolates showed minimal differences from the reference vaccine maps, raising the possibility that neurovirulence may be restored by a small number of genetic changes. For many isolates, changes were also detected in the mobilities and processing rates of the virus proteins.

\section{INTRODUCTION}

Immunization with live virus oral poliovaccines is highly effective in preventing poliomyelitis (Paccaud, 1979). The oral poliovaccine strains currently used were selected as spontaneous mutants of wild isolates following numerous passages in simian extraneural cells and tissues (Sabin \& Boulger, 1973).

Despite the many advantages of using attenuated viruses to produce conditions resembling natural infections, a general concern with live virus vaccines is the potential of the viruses to revert to virulence upon replication in humans. Opportunities for reversion appear to be clearly present because the oral poliovaccine strains are probably multisite mutants of the revertible missense class (Nomoto et al., 1979; Kew et al., 1980; Nottay et al., 1981; O. M. Kew, M. A. Pallansch and R. R. Rueckert, unpublished results), and several lines of evidence indicate that the vaccines can undergo genetic variation upon human intestinal passage (Sabin, 1957; Melnick, 1961; Jarzabek et al., 1976; Nottay et al., 1981). Indeed, in developed countries a significant fraction of the few remaining annual cases of paralytic poliomyelitis occur among vaccinees and their contacts (Schonberger et al., 1976). The problem of vaccine-associated disease arises most frequently with the vaccines of serotypes 2 and 3 (Schonberger et al., 1976). In the present study, we examined isolates of these serotypes from patients whose cases had an epidemiological association with the vaccine. Using the technique of oligonucleotide mapping of the poliovirion RNAs, we showed that all isolates were, in fact, vaccine-derived, and that some had extensively altered genomes. For several 
isolates, genome changes were associated with electrophoretically detectable changes in both the capsid and non-capsid virus proteins.

\section{METHODS}

Cells. A continuous line of human amnion cells (FL), grown as monolayers in Eagle's minimum essential medium (MEM) containing 10\% foetal calf serum (FCS), was used for propagation of high-titre virus stocks and in all labelling experiments.

Virus. The reference oral vaccine strains P712 Ch 2ab (Sabin type 2) and Leon $12 \mathrm{a}_{1} \mathrm{~b}$ (Sabin type 3) were provided by A. Sabin. They were labelled in the sixth cell culture passages of the original specimens. Clinical isolates from presumptive vaccine-associated cases of paralytic poliomyelitis (Table 1) were obtained through the World Health Organization and were sent to us by D. Magrath. They were passaged 1 to 4 times in primary monkey kidney cells before we received them, and were labelled in the third FL passage after receipt. To minimize selective conditions during in vitro propagation of the virus samples, clinical isolates were not plaque-purified.

Oligonucleotide mapping of poliovirus RNAs. The genome RNAs from purified poliovirions were analysed by two-dimensional electrophoresis of the ribonuclease $\mathrm{T}_{1}$-resistant oligonucleotides. Our procedures have been described in detail elsewhere (Nottay et al., 1981); therefore, only a brief outline is given here. Poliovirus-infected (20 to 40 p.f.u. cell) FL cells were labelled $\left(10 \mathrm{mCi}\right.$ in five $150-\mathrm{cm}^{2}$ monolayer cuitures) with ${ }^{32} \mathrm{P}$ lorthophosphate (New England Nuclear) at $2 \mathrm{~h}$ post-infection. After further incubation at $35^{\circ} \mathrm{C}$, when severe cell destruction was observed (generally at 16 to $24 \mathrm{~h}$ post-infection), the cultures were frozen and thawed three times. Polidvirions were concentrated from the clarified culture supernatant by polyethylene glycol precipitation, and purified by recovering the $150 \mathrm{~S}$ fraction from sucrose gradients.

Phenol-extracted RNA $\left(5 \times 10^{6}\right.$ or $\left.20 \times 10^{6} \mathrm{ct} / \mathrm{min}\right)$ from virions disrupted by SDS and 2-mercaptoethanol (2-ME) was digested in the presence of $100 \mu \mathrm{g}$ carrier tRNA with 100 units ribonuclease $T_{1}$ (RNase $T_{1}$, Calbiochem) for $30 \mathrm{~min}$ at $37^{\circ} \mathrm{C}$. Digests were resolved in the first dimension on gels $(15 \times 45 \times 0.15 \mathrm{~cm})$ of $8 \%$ polyacrylamide- $6 \mathrm{M}$-urea, adjusted to $\mathrm{pH} 3.3$ with citric acid. Electrophoresis was at $480 \mathrm{~V}\left(4^{\circ} \mathrm{C}\right)$ until the bromophenol blue (BPB) dye in the sample had migrated $21.5 \mathrm{~cm}$. The second dimension gel $(35 \times 43 \times 0.15$ $\mathrm{cm}$ ) contained $22 \%$ polyacrylamide in $50 \mathrm{~mm}$-tris-borate $\mathrm{pH} 8.2$, and was electrophoresed at $10 \mathrm{~W} /$ gel until the BPB dye had migrated $28 \mathrm{~cm}$. The pattern of oligonucleotide separation was visualized by autoradiographic exposure $\left(4^{\circ} \mathrm{C}\right)$ of du Pont Cronex- 4 medical X-ray film with an intensifying screen.

$S D S$-polyacrylamide gel electrophoresis (SDS-PAGE) of intracellular virus proteins. Poliovirus proteins were labelled and electrophoretically separated essentially as described by Nottay et al. (1981). FL monolayers in $35 \mathrm{~mm}$ dishes were infected at high multiplicity (>30/cell). Following attachment $\left(30 \mathrm{~min}, 25^{\circ} \mathrm{C}\right.$ ) they were incubated at $35^{\circ} \mathrm{C}$ in $\mathrm{MEM}$ lacking methionine and containing $2 \% \mathrm{FCS}$ and $2 \mu \mathrm{g} / \mathrm{ml}$ actinomycin D. After $3.5 \mathrm{~h}$ incubation, the cultures were labelled for $60 \mathrm{~min}$ with $50 \mu \mathrm{Ci}\left[{ }^{35} \mathrm{~S}\right]$ methionine (New England Nuclear), followed by a $60 \mathrm{~min}$ chase in the presence of $10 \mathrm{~mm}$-unlabelled methionine. The monolayers were solubilized in 5\% SDS-1\% dithiothreitol-50 mu-tris- $\mathrm{HCl} \mathrm{pH} 6 \cdot 8-10 \%$ glycerol. Lysates were heated at $100^{\circ} \mathrm{C}(2 \mathrm{~min})$ and sonicated before SDS-PAGE. Gels (24.5 $\times 12.5 \times 0.15 \mathrm{~cm}$ ) contained $50 \mathrm{mM}$-sodium phosphate $\mathrm{pH} 7 \cdot 1-0.1 \%$ SDS-0.5 M-urea, and were cast as linear 8 to $12 \%$ polyacrylamide gradients below $2.5 \mathrm{~cm}$ spacers of similar composition but containing $5 \%$ polyacrylamide. Electrophoresis was at $150 \mathrm{~V}$ until the xylene cyanol marker dye added to the sample had migrated $20 \mathrm{~cm}$. Virus protein bands were visualized by fluorographic ( $\mathrm{En}^{3} \mathrm{Hance}$, New England Nuclear) exposure of Cronex-4 medical $X$-ray film. 
Table 1. Poliomyelitis case isolates*

\begin{tabular}{|c|c|c|c|c|c|c|}
\hline Isolate & Serotype & $\begin{array}{c}\text { Age of } \\
\text { patient }\end{array}$ & $\begin{array}{c}\text { Association } \\
\text { with vaccine }\end{array}$ & $\begin{array}{l}\text { Illness } \\
\text { at day } \\
\text { after } \\
\text { exposure }\end{array}$ & $\begin{array}{l}\text { Virus } \\
\text { isolated } \\
\text { at day of } \\
\text { illness }\end{array}$ & $\begin{array}{c}\text { Source } \\
\text { of } \\
\text { specimen }\end{array}$ \\
\hline 105 & 2 & $9 \mathrm{~m}$ & Vaccinee: TOPV & 15 & 6 & Stool \\
\hline 117 & 2 & $7 \mathrm{~m}$ & Contact: MOPV2 & 5 & 6 & Stool \\
\hline 120 & 2 & $8 \mathrm{~m}$ & [Contact]: TOPV & 70 & 3 & Spinal cord $\S$ \\
\hline 130 & 2 & $13 \mathrm{~m}$ & [Contact]: MOPV2 & 77 & 9 & Stool \\
\hline 140 & 2 & $15 \mathrm{~m}$ & [Contact]: TOPV & 14 & 5 & Stool \\
\hline 147 & 2 & $13 \mathrm{~m}$ & Contact: TOPV & 42 & 7 & Stool \\
\hline 151 & 2 & $4 \mathrm{n}$ & Contact: TOPV & 71 & 9 & Stool \\
\hline 154 & 2 & $36 y$ & Contact: TOPV & 27 & 8 & Stool \\
\hline 155 & 2 & $33 \mathrm{y}$ & Contact: TOPV & 24 & 4 & Stool \\
\hline 185 & 2 & $29 y$ & Contact: TOPV & 10 & - & Stool \\
\hline 188 & 2 & $28 \mathrm{y}$ & Contact: TOPV & 25 & 3 & Stool \\
\hline 106 & 3 & $5 \mathrm{~m}$ & Vaccinee: TOPV & 14 & 16 & Medulla§ \\
\hline 115 & 3 & $14 \mathrm{~m}$ & Vaccinee: TOPV & 18 & 6 & Medulla \\
\hline 116 & 3 & $27 \mathrm{y}$ & Contact: TOPV & 22 & 4 & Stool \\
\hline 119 & 3 & $6 \mathrm{~m}$ & Vaccinee: TOPV & 14 & 4 & Spinal cord $\S$ \\
\hline 122 & 3 & $3 \mathrm{~m}$ & Contact: MOPV 3 & 19 & 10 & Stool \\
\hline 131 & 3 & $9 \mathrm{~m}$ & Vaccinee: MOPV3 & 16 & 8 & Stool \\
\hline 132 & 3 & $20 \mathrm{~m}$ & Contact: MOPV3 & 35 & 2 & Stool \\
\hline 146 & 3 & $24 \mathrm{~m}$ & Contact: TOPV & 21 & 7 & Stool \\
\hline 156 & 3 & $33 \mathrm{y}$ & Contact: TOPV & 26 & 6 & Stool \\
\hline 158 & 3 & $4 \mathrm{~m}$ & Contact: TOPV & 35 & - & Stool \\
\hline 186 & 3 & $42 \mathrm{~m}$ & Contact: TOPV & - & 11 & Stool \\
\hline
\end{tabular}

* Epidemiological and clinical data provided by I. Dömök, World Health Organization.

$\dagger$ Age of patient: $m$, months; $y$, years.

$\ddagger[$ Contact], possible contact. TOPV, Trivalent oral poliovaccine (Sabin). MOPV, Monovalent oral poliovaccine (Sabin), serotype indicated by number.

$\S$ Fatal case.

\section{RESULTS}

\section{Oligonucleotide maps of isolates related to the types 2 and 3 oral vaccines}

Oligonucleotide maps of types 2 and 3 poliovirus clinical isolates from presumptive oral vaccine-associated cases (Table 1) are shown in Fig. 1 and 2. All maps clearly resemble the reference maps of the corresponding oral vaccine. Maps of wild isolates of type 2 (three strains examined) and type 3 (10 strains examined) polioviruses were quite different from those of the vaccine strains (O. M. Kew et al., unpublished results). These observations parallel our previous findings with type 1 polioviruses (Nottay et al., 1981) that the oligonucleotide maps of epidemiologically distinct wild polioviruses differed from those of the vaccine strains and from each other. Similar conclusions have been presented by Minor (1980) for type 3 poliovirus. In general, the maps of unrelated poliovirus strains differ from each other as greatly as the Sabin 2 map (Fig. 1) differs from that of Sabin 3 (Fig. 2). Thus, the mapping data presented here appear to confirm the epidemiological classification of the cases, including all of the contact cases, as vaccine-associated.

Maps of most isolates differed from the vaccine reference maps by at least one or two spots. From numerous duplicate mapping studies we have found the oligonucleotide spot patterns to be highly reproducible. No two maps differed from the reference map in the same way (Fig. 1 and 2). Moreover, some isolates appeared to be highly modified from the vaccine, for example, isolate 151 (type 2) and isolate 116 (type 3). Other isolates showed few map changes. Type 2 isolate 120 , spinal cord virus from a fatal case, was particularly interesting because no significant differences from the vaccine map were detected. Similarly, another fatal case neural 


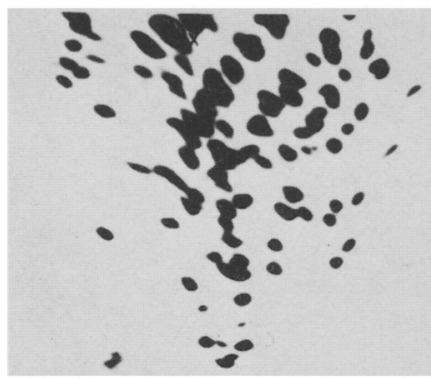

Sabin 2

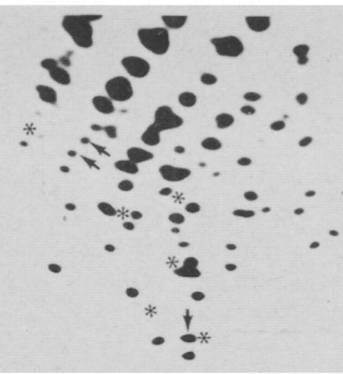

105

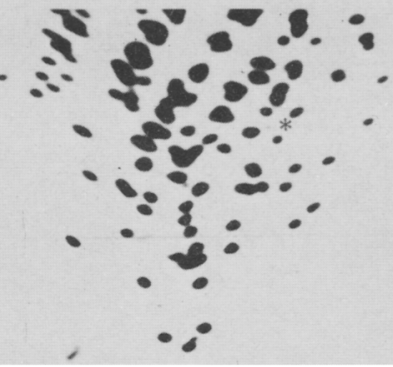

117

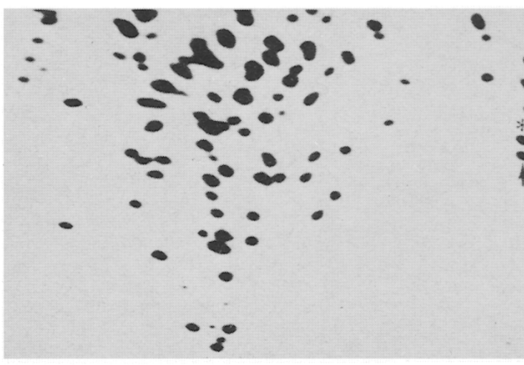

120

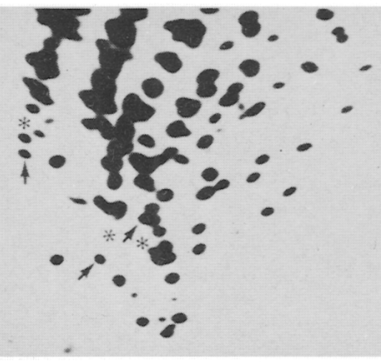

130

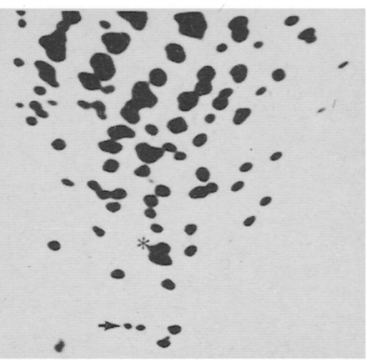

140

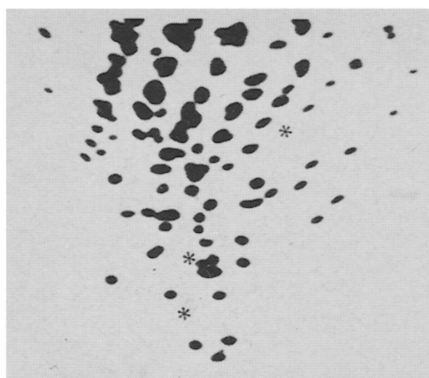

147

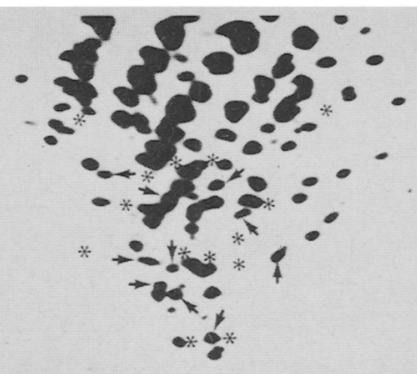

151

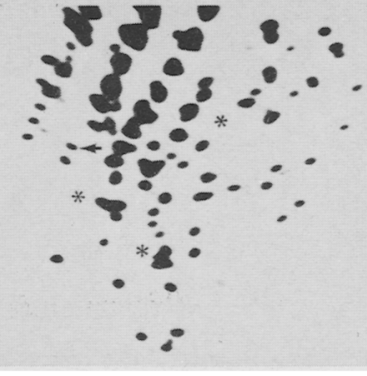

154

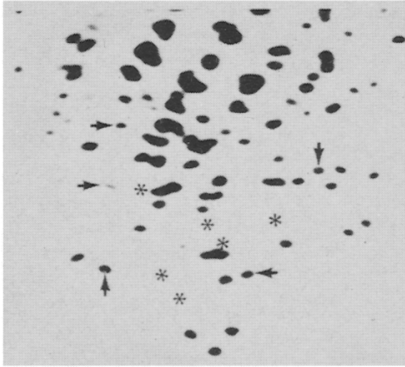

155

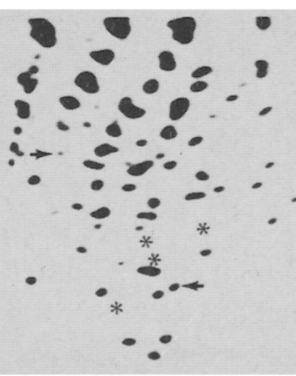

185

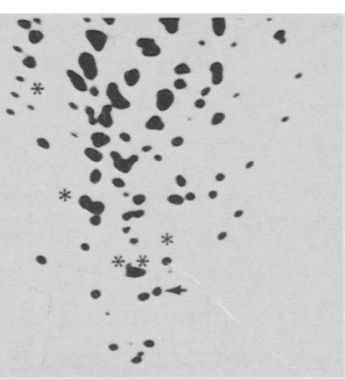

188

Fig. 1. Oligonucleotide map of the Sabin type 2 oral vaccine strain, P712 Ch $2 \mathrm{ab}$, compared with maps of type 2 poliovirus isolates from patients with paralytic cases of poliomyelitis having epidemiological association with the oral vaccine. For each pattern electrophoresis in the first dimension $(8 \%$ polyacrylamide, $6 \mathrm{M}$-urea $\mathrm{pH} 3.3$ ) was from left to right, and in the second dimension (22\% polyacrylamide, $50 \mathrm{~mm}$-tris-borate $\mathrm{pH} 8.2$ ) from bottom to top. Differences in the case isolate patterns from the pattern of the vaccine reference strain are indicated by arrows (new spots) and asterisks (missing spots). 


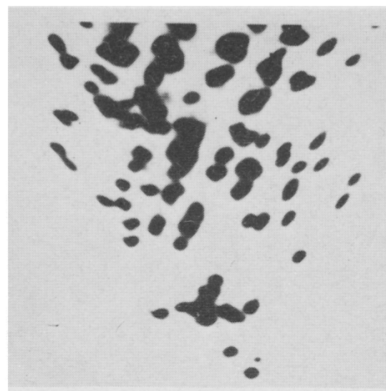

Sabin 3

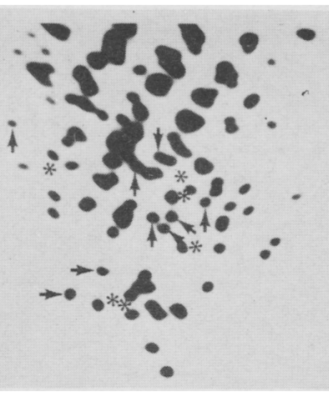

106

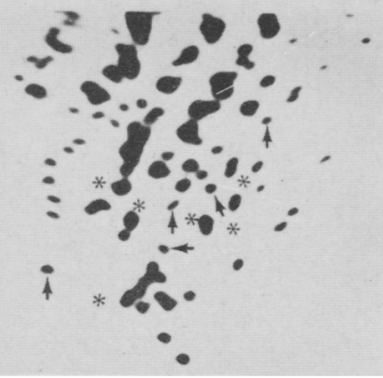

115

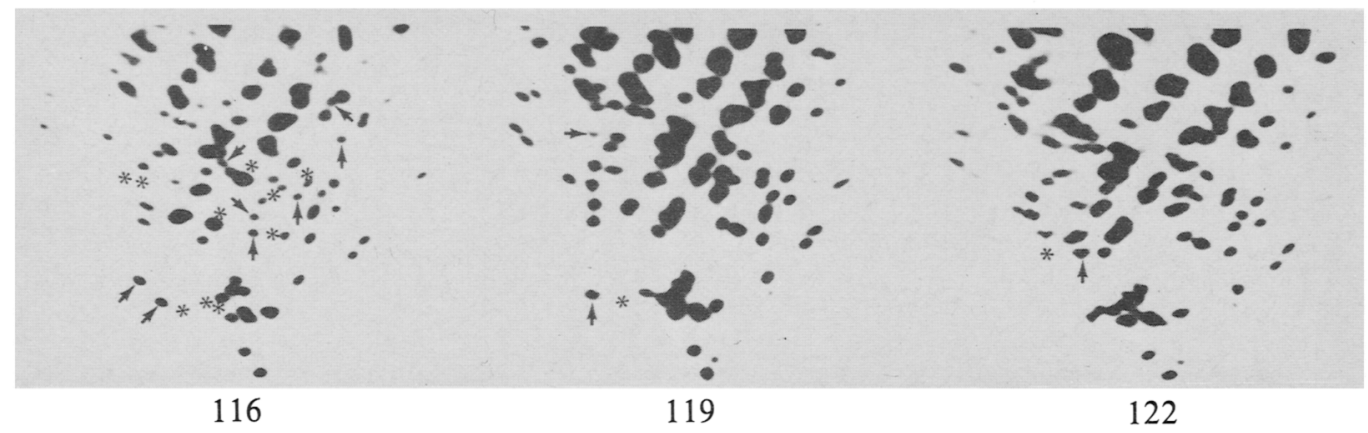

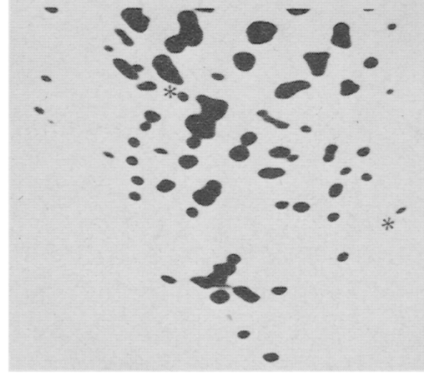

131

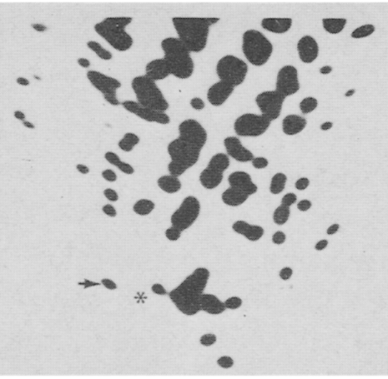

132

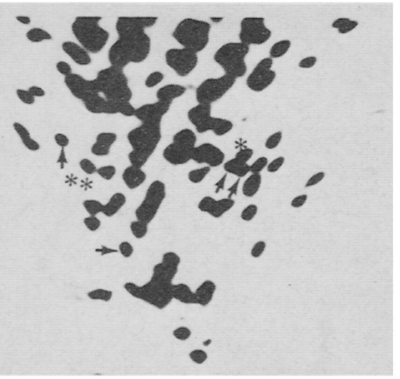

146

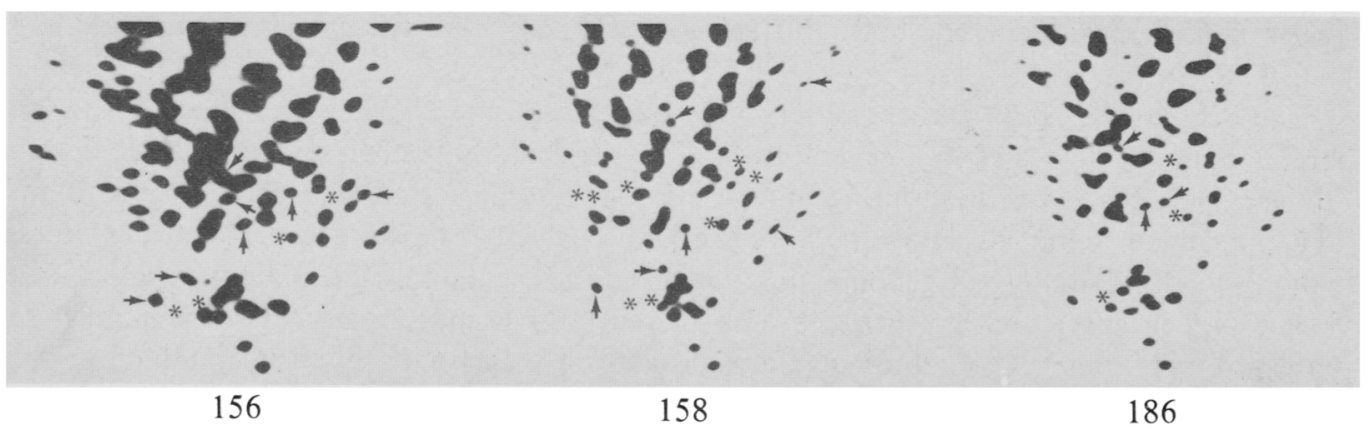

Fig. 2. Oligonucleotide maps of the Sabin type 3 oral vaccine strain, Leon $12 a_{1} b$, and isolates from vaccine-associated cases. Symbols are as described in Fig. 1. 
Table 2. Oligonucleotide changes in type 2 and 3 oral vaccine strains upon replication in

\section{humans}

$\begin{array}{lcccc}\text { Isolate } & \text { Serotype } & \text { Class* } & \begin{array}{c}\text { Period of human } \\ \text { replication } \\ \text { (days) }\end{array} & \begin{array}{c}\text { Number of detected } \\ \text { changes in T,-resistant } \\ \text { oligonucleotides } \ddagger\end{array} \\ 105 & 2 & \text { V } & 21 & 9 \\ 117 & 2 & \text { C } & 11+ & 1 \\ 120 \S & 2 & \text { C } & 73+ & 0 \\ 130 & 2 & \text { C } & 86+ & 6 \\ 140 & 2 & \text { C } & 19+ & 2 \\ 147 & 2 & \text { C } & 49+ & 3 \\ 151 & 2 & \text { C } & 80+ & 24 \\ 154 & 2 & \text { C } & 35+ & 4 \\ 155 & 2 & \text { C } & 28+ & 11 \\ 185 & 2 & \text { C } & - & 6 \\ 188 & 2 & \text { C } & 28+ & 6 \\ 106 \S & 3 & \text { V } & 30 & 15 \\ 115 \S & 3 & \text { V } & 24 & 11 \\ 116 & 3 & \text { C } & 26+ & 18 \\ 119 \S & 3 & \text { V } & 18 & 3 \\ 122 & 3 & \text { C } & 29+ & 2 \\ 131 & 3 & \text { V } & 24 & 2 \\ 132 & 3 & \text { C } & 37+ & 7 \\ 146 & 3 & \text { C } & 28+ & 11 \\ 156 & 3 & \text { C } & 32+ & 14 \\ 158 & 3 & \text { C } & - & 6 \\ 186 & 3 & \text { C } & - & \end{array}$

* V, Isolate from vaccinee; $\mathrm{C}$, isolate from contact.

$\dagger$ For contacts numbers indicate minimum days of human replication of vaccine.

$\ddagger$ From Fig. 1 and 2.

$\S$ Human neural tissue isolates.

isolate, 119 (type 3), found to be highly neurovirulent in monkeys (Minor, 1980), had a map that was very similar to the Sabin 3 reference map.

The oligonucleotide spot differences we detected between the maps of the case isolates and those of the reference vaccines are summarized in Table 2. No clear correlation was found between the extent of change from the vaccine as shown by oligonucleotide mapping and other reported case variables (patient age, source of specimen, period of infection before isolation). One might expect that isolates from contacts, because they had replicated in more than one person, would generally show greater change than isolates from vaccinees. However, no such relationships were apparent. For example, isolate 120 , with at least 73 days of human replication, showed no map differences, but isolate 105 , with a total of 21 days of human replication, had nine altered spots. Furthermore, changes were detected in both neural and intestinal isolates.

The degree of map differences observed between the human isolates and the oral vaccine strains strongly suggested that several cycles of mutation and selection have occurred within the vaccine virus population during human infection. Because the large, $R$ Nase $T_{1}$-resistant oligonucleotides comprise about $10 \%$ of the viral genome (M. Stewart, personal communication), the total number of genome mutations is in the range of 5 (the minimum factor, if all spot disappearances and appearances were paired) to 10 times greater than the number of observed spot changes. Accordingly, most isolates appear to be multisite mutants of the vaccine. Isolate 151 may differ from Sabin type 2 in as many as 100 to 200 sites, or in about $2 \%$ of the approx. 8000 (Lee et al., 1979) genome bases. In contrast, the neural isolate 120 may contain fewer than 10 mutations relative to the type 2 vaccine strain. 


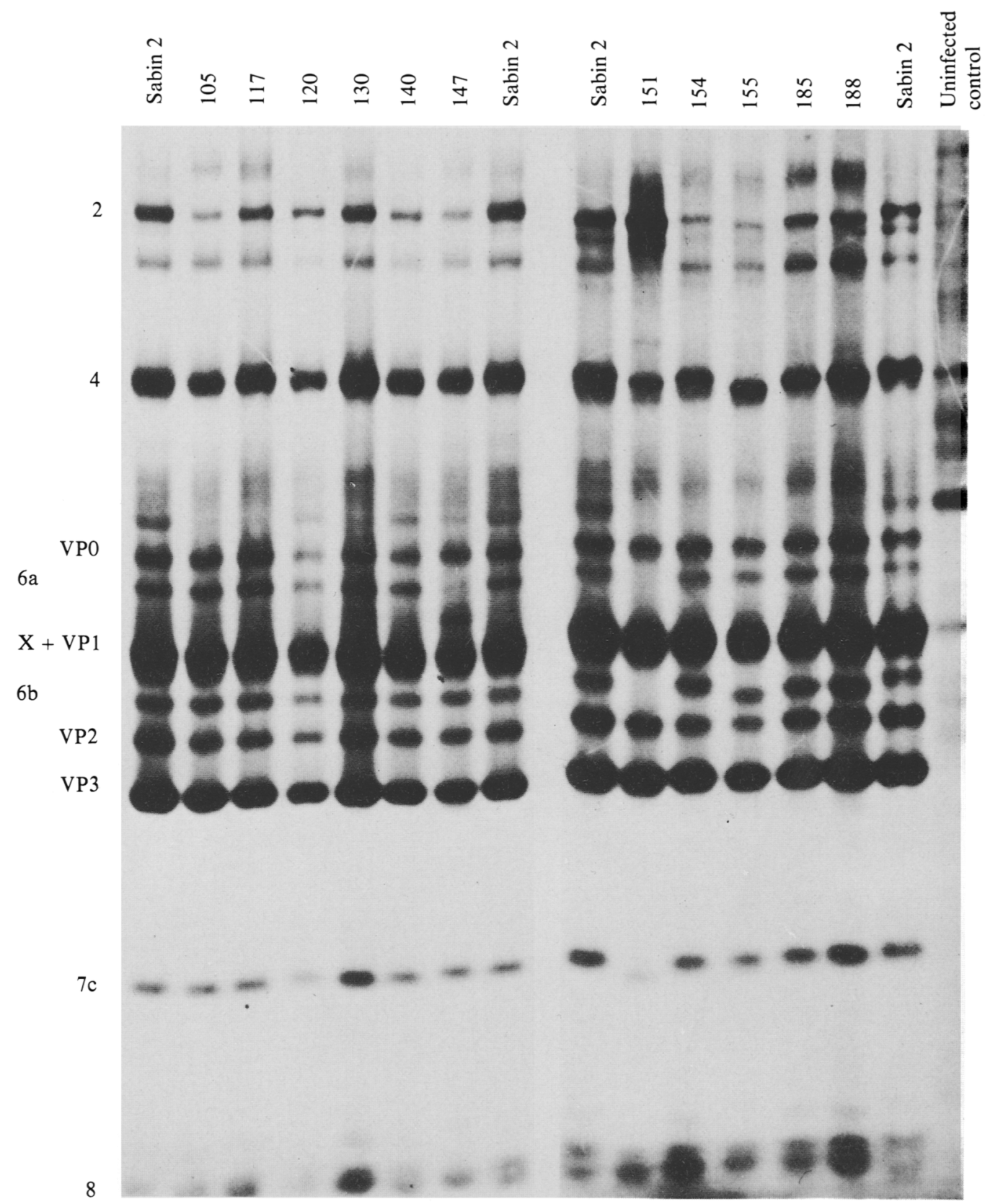

Fig. 3. SDS-polyacrylamide gels of ${ }^{35} \mathrm{~S} \mid$ methionine-labelled virus proteins produced in cells infected with Sabin type 2 or type 2 isolates from vaccine-associated cases.

Electrophoretically detectable differences in the virus proteins of the vaccine-related case isolates

For type 1 poliovaccine-derived isolates, alterations in the oligonucleotide maps were accompanied by shifts in the electrophoretic mobilities of the virus proteins (Nottay et al., 1981). The mobility shifts are believed to reflect changes in the composition of the virus proteins (Kew et al., 1980).

The intracellular virus proteins of the case isolates were compared with those of the vaccines by SDS-PAGE (Fig. 3 and 4). For the type 2 isolates, all migration patterns were 


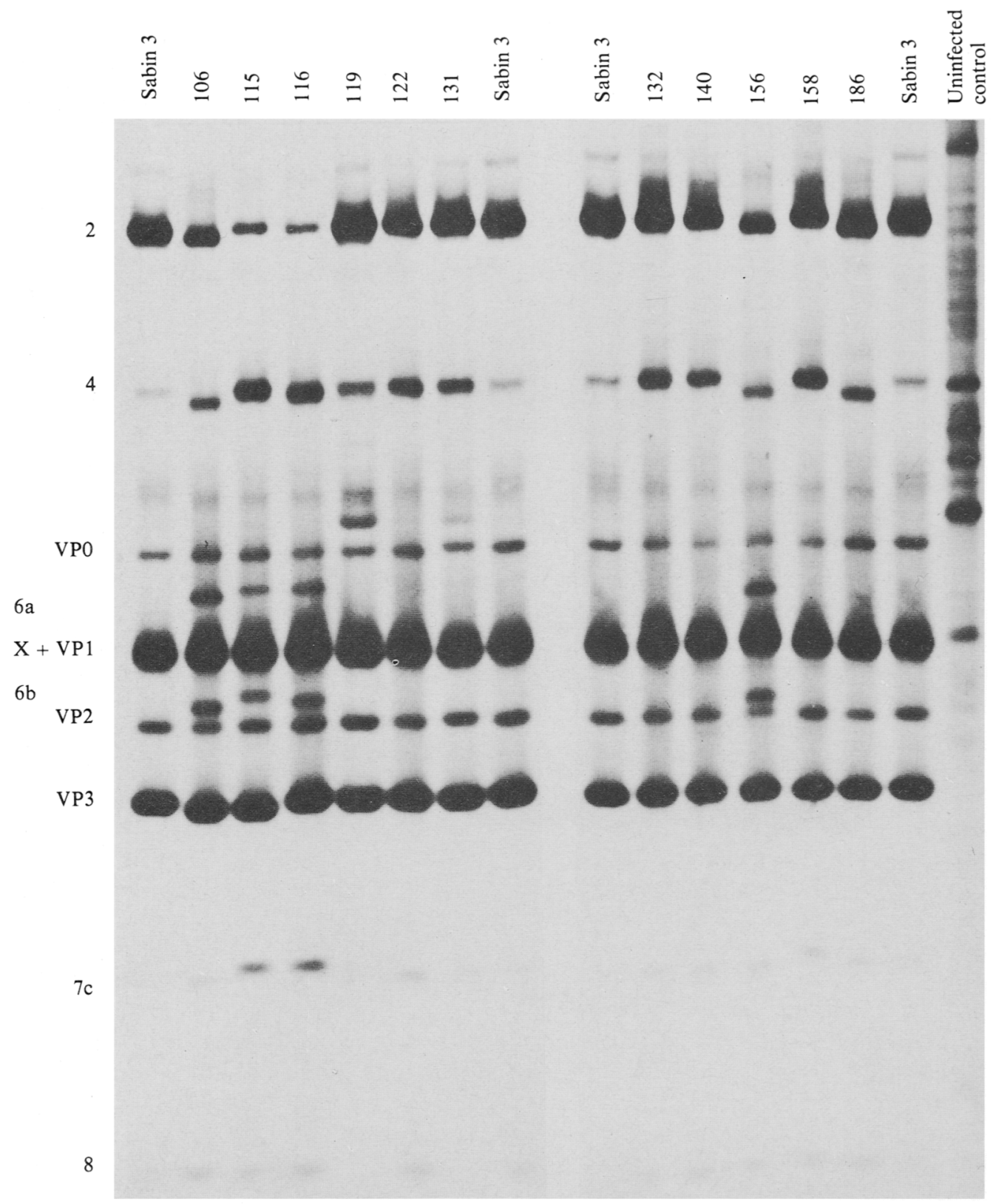

Fig. 4. SDS-polyacrylamide gels of virus intracellular proteins of Sabin type 3 or type 3 isolates from vaccine-associated cases.

similar to the vaccine reference pattern. Most, for example, showed strong 4 and $7 \mathrm{c}$ bands, which reflects the very rapid processing of their precursor 2, a distinctive feature of strains related to P712 Ch 2ab (Butterworth, 1973; O. M. Kew \& R. R. Rueckert, unpublished results). By SDS-PAGE, little change was seen in the capsid proteins of the type 2 isolates, although subtle differences in VP1 might not be detected because of its close migration with the non-capsid protein X. Most of the detected changes were in the proteins derived from the cleavage of $2: 4+7 c$, and by a second pathway, $6 a+6 b$ (Rueckert et al., 1979). Although 
the pattern for 120 was essentially indistinguishable from the Sabin 2 pattern, that of 151 differed by having increased amounts of 2 , little or no $6 \mathrm{a}$ and $6 \mathrm{~b}$, and a more rapidly migrating 7c. Similarly, several other strains showed small but reproducible mobility shifts in the 2 family. Proteins of the $1 \mathrm{~b} \rightarrow 2 \rightarrow 4$ cleavage pathway are components of the poliovirus RNA replicase (Flanegan \& Baltimore, 1979). Polypeptide 7c may correspond to the virus-specific protease described for encephalomyocarditis virus (Palmenberg et al., 1979). Changes in these proteins appear to have the potential for altering virus RNA synthesis and proteolytic processing of the virus proteins.

Isolates derived from Sabin 3 also showed changes in the 2 family proteins. Patterns of some isolates, for example 106,115, 116 and 156, showed less 2 but greater amounts of 6 a and $6 \mathrm{~b}$. Others showed altered mobilities for $4(106,116,156,186)$ and $7 \mathrm{c}(115,116)$, and small but reproducible increases in the mobility of VP3 $(106,115)$. The intracellular virus proteins of many of these same type 3 isolates were also examined by Minor (1980). Although different SDS-PAGE systems were used, the polypeptide changes we report here can also be seen in the patterns of Minor (1980).

Although SDS-PAGE is much less sensitive to changes in proteins than tryptic peptide analysis and may not detect all of the altered virus proteins, it does indicate in which proteins at least some of the mutational changes occur. Homologous poliovirus proteins which show mobility differences in SDS gels have, in fact, been found to have differences in their tryptic peptides (Kew et al., 1980). From these results, we conclude that human passage of the oral vaccines may select for mutational (probably substitutions) changes in the virus proteins, and that some isolates have sustained changes in more than one polypeptide.

\section{DISCUSSION}

Oral poliovaccines types 2 and 3, like type 1 polioviruses (Nottay et al., 1981), may also undergo genome variation upon replication in human beings. This basic finding alone is not new; the genetic instability of the oral poliovaccines was the subject of several earlier studies (Sabin, 1957; Melnick, 1961; Nakano et al., 1963; Jarzabek et al., 1976). The surprising findings in our work were the high degree of genome modification which may occur during replication in some people, and the somewhat contrasting suggestion that by some mutational pathways neurovirulence may be restored to the oral vaccines by a relatively small number of mutational events.

The extensive genome modifications of some isolates from vaccinees and contacts are most remarkable because the changes have apparently occurred during replication in only one or two persons. Oligonucleotide mapping suggested that some isolates had sustained changes in as many as 1 to $2 \%$ of the genome bases. This is far greater than the small (one or two oligonucleotide spots) differences between the maps of the types 2 and 3 oral vaccines and their respective wild parents (unpublished results). A similar 1 to $2 \%$ degree of genetic divergence was observed in a wild-type 1 poliovirus strain only after 13 months of epidemic transmission, presumably by a chain of infections involving many persons (Nottay et al., 1981).

It seems very unlikely that the extensively modified variants were pre-existent in the vaccine preparations and were thus merely amplified during intestinal replication. Although poliovaccine lots do show some heterogeneity (Nakano et al., 1979), the relatively controlled conditions of vaccine production in cell culture probably impose narrow limits on the genetic divergence of the virus population. Indeed, model statistical analyses of populations of the bacteriophage $\mathrm{Q} \beta$, which, like poliovirus (Cooper, 1969), has a highly mutable RNA genome, suggest that highly divergent variants are not simultaneously present in small virus populations (a typical vaccine dose is $10^{6}$ infectious particles) growing under constant conditions (Domingo et al., 1978). Thus, the observed multisite genome changes most likely 
occurred after several cycles of mutation and selection of new variants during replication in humans. The implications of this view are important. Despite careful production and rigorous testing of the oral vaccines, control of post-administration reversion appears to be beyond our current capabilities.

The nature of the selective pressures exerted on viruses replicating in human beings is poorly defined. Obvious mediators for change in a virus population are antibodies. However, many other factors must also play a role. For example, changes in the virus polypeptides were not restricted to the virion proteins, where alterations might be expected to occur in response to antibody pressure, but were also found in the non-capsid proteins, which are thought to function only intracellularly (Palmenberg et al., 1979). Moreover, antibody pressure would not appear to be an important selective factor in hypogammaglobulinemic vaccinees, yet considerable vaccine genome modification can occur during replication in these people as well (O. M. Kew et al., unpublished results).

In some respects the vaccine-derived strains examined here are atypical, because they were isolated from persons with paralytic disease, and vaccine-associated cases are very rare (Schonberger et al., 1976). Extensive modification of the vaccine strain genomes may be unusual, although small changes appear to occur frequently during normal immunizations (O. M. Kew et al., unpublished results). This is significant because only a small number of the appropriate changes appear necessary to recover neurovirulence. However, the full conditions allowing production of neurovirulent variants and their amplification, spread, and pathological expression must be quite unusual, because the incidence of vaccine-associated disease is very low.

We thank Fred Brown, Mark Pallansch and Roland Rueckert for their constructive comments and suggestions, and Marianne Stapp for excellent technical assistance.

\section{REFERENCES}

BUTTERWORTH, B. E. (1973). A comparison of the virus-specific polypeptides of encephalomyocarditis virus, human rhinovirus-1A, and poliovirus. Virology 56, 439-453.

COOPER, P. D. (1969). The genetic analysis of poliovirus. In The Biochemistry of Viruses, pp. 177-218. Edited by H. B. Levy. New York: Marcel Dekker.

DOMINGO, E., SABO, D., TANIGUCHI, T. \& WEISSMANN, c. (1978). Nucleotide sequence heterogeneity of an RNA phage population. Cell 13, 735-744.

FLANEGAN, J. B. \& BALTIMORE, D. (1979). Poliovirus polyuridylic acid polymerase and RNA replicase have the same viral polypeptide. Journal of Virology 29, 352-360.

JARZABEK, Z., SADOWSKI, W., KANTOCH, M., MAGRATH, D. \& KRAWCZYNSKI, K. (1976). Studies on the characteristics of poliovirus type 3. III. Strain characteristics after passage in man. Acta Virologica 20, 373-379.

KEW, O. M., PALLANSCH, M. A., OMILIANOWSKI, D. R. \& RUECKERT, R. R. (1980). Changes in three of the four coat proteins of oral poliovaccine strain derived from type 1 poliovirus. Journal of Virology 33, 256-263.

LEE, Y. F., KITAMURA, N., NOMOTO, A. \& WIMMER, E. (1979). Sequence studies of poliovirus RNA. IV. Nucleotide sequence complexities of poliovirus type 1 , type 2 and two type 1 defective interfering particle RNAs, and fingerprint of the poliovirus type 3 genome. Journal of General Virology 44, 311-322.

MeLnICK, J. L. (1961). Attenuated poliovirus vaccine: virus stability. In Poliomyelitis. Fifth International Poliomyelitis Conference, Copenhagen, pp. 384-402. Philadelphia: Lippincott.

MINOR, P. D. (1980). Comparative biochemical studies of type 3 poliovirus. Journal of Virology 34, 73-84.

NAKANO, J. H., GELFAND, H. M. \& COLE, J. T. (1963). The use of a modified Wecker technique for the serodifferentiation of type 1 polioviruses related and unrelated to Sabin's vaccine strain. II. Antigenic segregation of isolates from specimens collected in field studies. American Journal of Hygiene 78, 214-226.

nakano, M., matsukura, T., yoshil, K., Komatsu, T., mukoyama, A., UChida, N., Kodama, H. \& tagaya, I. (1979). Genetical analysis on the stability of poliovirus type 3 Leon $12 \mathrm{a}_{1} \mathrm{~b}$. Journal of Biological Standardization 7, 157-168.

NOMOTO, A., KAJIGAYA, S., SUZUKI, K. \& IMURA, N. (1979) Possible point mutation sites in LSc 2ab poliovirus RNA and a protein covalently linked to the 5'-terminus. Journal of General Virology 45, 107-117.

NOTTAY, B. K., KEW, O. M., HATCH, M. H., HEYWARD, J. T. \& OBIJESKI, J. F. (1981). Molecular variation of type 1 vaccine-related and wild polioviruses during replication in humans. Virology 107, 405-423. 
PACCAUD, M. F. (1979). World trends in poliomyelitis morbidity and mortality, 1951-1975. World Health Statistics Annual 32, 198-224.

PAlmenberg, A. C., PAllansCh, M. A. \& RUECKert, R. R. (1979). Protease required for processing picornaviral coat protein resides in the viral replicase gene. Journal of Virology 32, 770-778.

RUECKert, R. R., MATTHEWS, T. J., KEW, O. M., PALlANSCH, M. A., MCleAN, C. \& OMILIANOWSKi, D. (1979). Synthesis and processing of picornaviral polyprotein. In Molecular Biology of Picornaviruses, pp. 113-125. Edited by R. Perez-Bercoff. New York: Plenum Press.

SABIN, A. B. (1957). Properties and behaviour of orally administered attenuated poliovirus vaccine. Journal of the American Medical Association 164, 1216-1223.

SAbIN, A. B. \& BoulgER, L. R. (1973). History of Sabin attenuated poliovirus oral live vaccine strains. Journal of Biological Standardization 1, 115-118.

SCHONBERGER, L. B., MCGOWAN, J. E., JR. \& GREGG, M. B. (1976). Vaccine-associated poliomyelitis in the United States. American Journal of Epidemiology 104, 202-211.

(Received 13 April 1981) 